\title{
Abscisic acid confers salinity tolerance in Chlamydomonas reinhardtii at different stages of its life cycle
}

\author{
Said Abu-Ghosh ${ }^{1}, Z_{\text {vy Dubinsky }}{ }^{1}$, and David Iluz ${ }^{1}$ \\ ${ }^{1}$ Bar-Ilan University
}

June 16, 2020

\begin{abstract}
The effect of abscisic acid (ABA) to increase the osmotolerance of the freshwater microalga Chlamydomonas reinhardtii at its different stages of life cycle was investigated. Exogenously added ABA enhanced the growth and photosynthesis of C. reinhardtii during the vegetative stage. The hormone also increased the tolerance of this alga to oxidative stress during gamete formation under nutrient depletion and high salinity, as it supported their survival for a longer period. We show that the level of reactive oxygen species (ROS) generated in the ABA-treated cells was significantly less than that in the untreated cells under inhibiting $\mathrm{NaCl}$ concentrations. Cell size examination showed that ABA prevents cells from forming palmella when exposed to high salinity. All together, these results suggest that ABA increases the tolerance of C. reinhardtii to salt stress conditions.
\end{abstract}

\section{KEYWORDS}

Abscisic acid, Chlamydomonas, Growth, Osmotolerance, Photosynthesis, ROS, Salinity

\section{INTRODUCTION}

Green algae are photoautotrophic eukaryotes, which are the ancestors to higher plants (Ligrone, 2019) and, therefore, they are identical to each other in their basic metabolism, including photosynthesis and photoprotection (Delaux et al., 2015). Chlamydomonas reinhardtiiis a freshwater unicellular algal model species widely used for studying and revealing many biological aspects of microalgae relevant to higher plants such as evolution (Bell, 2005), biochemistry and physiology (Couso et al., 2018; Girolomoni et al., 2019; Juvale et al., 2016), mutant generation (Findinier et al. , 2017; Li et al., 2016;) and algae-based biofuel production (Scranton et al., 2015). Chlamydomonas cells are haploid, and under favorable growth conditions reproduce asexually during the dark phase of the light:dark cycle (Bruce \& Bruce, 1981). However, environmental stresses, especially nitrogen limitation, promote sexual reproduction inChlamydomonas, developing plus and minus gametes that mate and fuse to form a zygote, which undergoes meiosis to eventually release four new individual cells (Goodenough et al., 2007). It is well established that breeding, or outcrossing lines to generate hybrids in plants and animals can lead to segregants with new traits, a phenomenon known as heterosis (Shull, 1948), therefore sexual recombination inChlamydomonas is a useful approach to optimize new complex traits.

Salinization is the accumulation of salts, mainly sodium and chloride salts, in the soil, which is considered one of the main environmental limiting factors to global crop productivity (Munns \& Gilliham, 2015). Salinization also widely exists in aquatic environments that causes inhibition or induces cell death to many photosynthetic non-halophytic organisms including freshwater microalgae. High salt stress arrests cell division, where growth rate is immediately impacted, halts motility, reduces size, decreases photosynthesis in Chlamydomonas (Chen et al., 2016; Khona et al. , 2016).

Exposure to $\mathrm{NaCl}$ concentrations between 100 and $150 \mathrm{mM}$ (equivalent to saline soils) and provokes formation 
aggregates of smaller cells known as "palmelloids". Moreover, under sever salt stresses the levels of ROS increase in the chloroplasts as byproducts of photosynthesis (Asada et al., 1999; Rizhsky et al., 2003) resulting in oxidative damage to DNA, proteins and membranes, which eventually lead to cell death (Takahashi and Murata, 2008). To reduce the toxicity of ROS to improve cell stress tolerance, photosynthetic organisms have evolved several anti-oxidant and free-radical scavenging systems (Miller et al., 2010; Quesada and Fernández, 1994).

The plant hormone abscisic acid (ABA) plays significant roles in many biological pathways in the development and growth of plants including seed germination and bud dormancy (Han et al., 2018; Santner et al., 2009). $\mathrm{ABA}$ is also known in its vital involvement in plant tolerance to both biotic and abiotic stresses such as heavy metals, extreme temperature variations and high salinity (Suzuki et al., 2012; Vishwakarma et al., 2017), and in controlling stomata aperture to prevent water loss during drought (Mittler \& Blumwald, 2015). Traditionally, plant hormones and synthetic metabolism regulators are used in research to elucidate phenotypical plant responses to external stimuli and their control mechanisms. It was reported that exogenous abscisic acid (ABA) modulates the abundance of mitochondrial reactive oxygen species (ROS) in plants via inhibition of cytochrome c oxidase (COX) or non-mitochondrial ROS signaling through inhibition of NADPH oxidases (Piantadosi, 2008), thus reducing ROS accumulation toxicity.

Although the effect of ABA in enhancing the growth of Chlamydomonas has been demonstrated (Chokshi et al., 2017; Yoshida et al., $2003 \&$ 2004), the functional role of it in increasing microalgal osmotolerance and photosynthesis under salt stress remains unclear. Therefore, the objective of this study is to achieve a better understanding of how exogenous $\mathrm{ABA}$ regulates algal photosynthesis, tolerance and acclimation to $\mathrm{NaCl}$ stress, and to compare bioaccumulation of ROS in ABA-treated and ABA-untreated slat stressed cells. Moreover, this work examines the effects of $\mathrm{ABA}$ on gametes formation and surviving under inhibiting $\mathrm{NaCl}$ concentrations.

\section{MATERIALS AND METHODS}

\section{Strain, Culture Conditions, and Growth Monitoring}

Chlamydomonas reinhardtii strain CC-124 (mt- [137C]) was generously obtained from laboratory of Dr. Iftach Yacoby, Tel Aviv University, which was originally purchased from Chlamydomonas Resource Center, University of Minnesota. The seed cultures were grown at $23{ }^{\circ} \mathrm{C}$ on liquid Tris-acetate-phosphate (TAP) medium (Harris, 1989) in flasks capped with a silicone sponge, and were shaken at $100 \mathrm{rpm}$ under continuous illumination of $150 \mu \mathrm{mol}$ photons $\mathrm{m}^{-2} \mathrm{~s}^{-1}$ at $16: 8 \mathrm{~h}$ of light:dark period, and ambient $\mathrm{CO}_{2}$ concentrations. Cell growth was determined by optical density measurements at $750 \mathrm{~nm}\left(\mathrm{OD}_{750}\right)$ using a NanoDrop 2000c spectrophotometer (Thermo Scientific, Wilmington, DE). Cell count was performed with a BD FACSCalibur flow cytometer (Breda, Netherlands). Cultures were kept in the log phase with $\mathrm{OD}_{750}$ between $0.1-0.3$ which is corresponding to a cell number of $3-9 \times 10^{5}$ cells $* \mathrm{~mL}^{-1}$ by dilution every $48 \mathrm{~h}$ to minimize self-shading.

\section{Determination of salt stress}

Exponential cultures of $C$. reinhardtii were inoculated onto TAP medium with elevated amounts of $\mathrm{NaCl}$ to final concentrations of $0,100,125,175,200,250$ and $300 \mathrm{mM}$, with initial $\mathrm{OD}_{750}$ of 0.1 . The cultures were incubated at optimal conditions, in triplicates, and growth response was measured after $72 \mathrm{~h}$ of treatment.

\section{Effect of ABA on C. reinhardtii in dense cultures}

C. reinhardtii cells were harvested by centrifugation at $1500 \mathrm{~g}$ for $10 \mathrm{~min}$ and then inoculated onto $50 \mathrm{ml}$ of fresh Tris-minimal medium (Gorman and Levine, 1965) to an $\mathrm{OD}_{750}$ of 1 . For ABA experiments, stock of ABA solution was prepared by dissolving ABA powder (Duchefa Biochemie) in HPLC-grade ethanol to a final concentration of $100 \mathrm{mM}$. The stock solution was very concentrated to minimize the added volume to the algal cultures. To investigate the effect of ABA on the growth of $C$. reinhardtii under salt stress, two different concentrations of ABA were checked. Cultures were treated with 0 (control), $500 \mu \mathrm{M}$ ethanol (mock), 50 and $500 \mu \mathrm{M} \mathrm{ABA}$, and $\mathrm{NaCl}$ was added to the cultures to a final concentration of $125 \mathrm{mM}$ 
(this concentration was chosen based on the results of the previous section). The cultures were then further incubated for $48 \mathrm{~h}$ under continuous illumination of $100 \mu \mathrm{mol}$ photons $\mathrm{m}^{-2} \mathrm{~s}^{-1}$ for $48 \mathrm{~h}$ without dark periods.

\section{Cell viability}

Cell number of exponential cultures was adjusted to $2 \times 10^{3}$ cells $\mathrm{mL}^{-1}$ in fresh TAP medium containing 0 (control), $50 \mu \mathrm{M}$ ethanol (mock) and $50 \mu \mathrm{M}$ ABA then algal inoculates of $50 \mu \mathrm{l}$ were spotted on TAP$1.5 \%$ Difco agar plates with and without $125 \mathrm{mM}$ of $\mathrm{NaCl}$ (6 plates each treatment). The plates were then incubated for 6-8 days till no more colonies were developed. The survival rate of the cells incubated with $\mathrm{NaCl}$ was indicated as a percentage to the control colony forming units (CFUs) in which the cells were incubated without $\mathrm{NaCl}$.

Monitoring of photosynthetic activity To enable measuring net photosynthetic $\mathrm{O}_{2}$ production rates, a mini photobioreactor was equipped with a multi-sensor port, AlgaeGrowth-PAM, designed in the laboratory of Prof. Zvy Dubinsky at Bar Ilan University, and manufactured by Heinz Walz (Effeltrich, Germany) (Supplementary Fig. S1), controlled by custom WinControl-3 software (Fig. S4). Cultures were collected after $24 \mathrm{~h}$ of different treatments with continuous optimal illumination, then were loaded in the insolated metabolic chamber, dark-adapted for $10 \mathrm{~min}$ at $23{ }^{\circ} \mathrm{C}$ until the maximum quantum yield ( Fv/Fm) was reached, then the cultures were illuminated with a stepwise increasing actinic light of $0,110,150,230,330$, 480 and $1000 \mu \mathrm{mol}$ photons $\mathrm{m}^{-2} \mathrm{~s}^{-1}$ for 2 min each step for a total period of $12 \mathrm{~min}$. Oxygen production was monitored by an ultra-sensitive optical oxygen sensor (Pyroscience, Ltd) that uses a fluorescence signal (synthetic dye that changes fluorescence intensity with $\mathrm{O}_{2}$ concentration) under vigorous stirring. Delta $\mathrm{O}_{2}$ was calculated and exponential fitting curves were performed to extract Pmax values.

\section{ROS generation experiment}

Cells were harvested by centrifugation at $1500 \mathrm{~g}$ for $10 \mathrm{~min}$ the washed 3 times with sterile double distilled water before suspended in TAP medium. Cultures were then treated with $125 \mathrm{mM}$ of $\mathrm{NaCl}$ and with or without $\mathrm{ABA}$ and were illuminated and shaken-incubated for $3 \mathrm{~h}$, as described above in materials and methods. One-milliner samples were collected and stained with $20 \mu \mathrm{M}$ of $\mathrm{H}_{2}$ DCFDA for $30 \mathrm{~m}$ (Colle'n, and Davison, 1997). The fluorescence of the dye was measured by a Fortessa flow cytometer (Breda, Netherlands). Cell vitality was carried out by inoculating of $50 \mu \mathrm{l}$ drops of Chlamydomonascultures after $24 \mathrm{~h}$ of treatment on TAP-1.5\% Difco agar plates.

\section{Microscope imaging}

$\mathrm{H}_{2}$ DCFDA stained cells were visualized by a fluorescence microscope Leica SP8 confocal microscope equipped with Olympus DP10 digital camera, fitted with a 100 W High Pressure Mercury Burner with a lateral resolution down to $140 \mathrm{~nm}$. Using CUDA based processing, differential interference contrast (DIC), chloroplast autofluorescence (excitation at $633 \mathrm{~nm}$ and emission at $670 \mathrm{~nm}$ ) and DCF-DA epifluorescence (excitation: $488 \mathrm{~nm}$, emission: $525 \mathrm{~nm}$ ) images were obtained at $20 \times$ magnification.

\section{Cell diameter and palmella formation}

Cell diameter was determined by means of fluorescence activated cell sorter (FACS, BD Fortessa, USA) using side scatter pulse width (SSC-W) data from cells against size calibration bead standards of polystyrene (Spherotech, USA). Briefly, six different bead standards ranging between $3 \mu \mathrm{m}$ and $16 \mu \mathrm{m}$ were used to plot a calibration standard curve of amplifier gains where the pulse width was independent of peak height and peak area. The curve was then fitted with a linear curve according to Sharpless and Melamed (1976), and was used to transform the median SSC-W data from a microalgal cell population of $1 \times 10^{6}$ cells* $\mathrm{mL}^{-1}$ into a median cell diameter (Supplementary Fig. 2).

Effect of ABA on gametogenesis and gamete survival under salt stress, long term experiment

Cells were diluted to $\sim 1 \times 10^{5}$ cells $^{*} \mathrm{~mL}^{-1}$ and were grown vegetatively to a concentration of $\sim 1 \times 10^{6}$ cells $^{*} \mathrm{~mL}^{-1}$, then were centrifuged at $1500 \mathrm{~g}$ for $10 \mathrm{~min}$ and washed twice with $\mathrm{N}$-deficient (N) TAP medium before resuspension in $10 \% \mathrm{~N}$ medium. Cultures were then treated with ABA or ethanol 
before adding $125 \mathrm{mM} \mathrm{NaCl}$ as described above and were shaken-incubated at $200 \mathrm{rpm}$ under continuous illumination of $150 \mu \mathrm{mol}$ photons $\mathrm{m}^{-2} \mathrm{~s}^{-1}$ without dark periods, and monitoring the optical density every 24 $\mathrm{h}$ for $72 \mathrm{~h}$.

\section{Statistical analysis}

The experimental design included measurement of 6 cultures per treatment for the vegetative cells experiments (except photosynthesis measurements 2 cultures per treatment) and 3 cultures per treatment for the gametes' experiments. The effects of treatments and their interactions were analyzed using Student's $t$-test. Values represent means $\pm \mathrm{SD}$.

\section{RESULTS}

\section{ABA enhances the growth and photosynthesis of $C$. Reinhardtii under salt stress}

To investigate the sensitivity of Chlamydomonas to $\mathrm{NaCl}$, cells were grown in TAP medium supplemented with increasing concentrations of $\mathrm{NaCl}$ from $100-300 \mathrm{mM}$. After $72 \mathrm{~h}$ of incubation the growth was reduced in which $60 \%$ of the cells survived at $125 \mathrm{mM} \mathrm{NaCl}$, compared to the unstressed control (Supplementary Fig. S3). The negative effect of the salt on cell growth was more pronounced at higher concentrations such as $250 \mathrm{mM} \mathrm{NaCl}$. However, Chlamydomonas is not fully arrested by $\mathrm{NaCl}$ at higher concentration, after longer incubation period we still detected slow growth of the cells (Supplementary Fig. S3). Therefore, the concentration of $125 \mathrm{mM} \mathrm{NaCl}$ was considered for salt stress treatments in this study.

Dimethylsulfoxide (DMSO) is widely used as a carrier solvent for small molecules in biological assays, with low toxicity at concentrations $<10 \%$ (Szmant, 1975). In previous research DMSO was used in ABA experiments on C. reinhardtii (Yoshida et al. , 2003; Yoshida et al. , 2004), however its interfering influence on the grown was not evaluated. In this study, DMSO was used as a carrier solvent for ABA in low concentration of $50 \mu \mathrm{M}$. After $3 \mathrm{~d}$ of cultivation the growth increased $40 \%$ compared to control (Supplementary Fig. S4). Therefore, and instead, we decided to use methanol as a solvent for ABA for the experiments. To test whether ethanol has a positive impact on growth or not, we ran a mock treatment that contains only ethanol of a final concentration of $50 \mu \mathrm{M}$ and $C$. reinhardtii cells, along with the other treatments.

We next set out to confirm whether ABA enhances the growth of $C$. reinhardtii under optimal and salt stress conditions or not. Fig. 1 shows that the addition of $50 \mu \mathrm{M}$ and $500 \mu \mathrm{M}$ ABA to dense cultures of C. reinhardtii increases about $10 \%$ of the growth without a lag phase compare to the untreated control, while adding ethanol as a mock treatment reduced the growth $20 \%$ after $48 \mathrm{~h}$ of incubation under favorable conditions (Fig. 1A). However, when ABA was added to cultures grown on TAP medium containing $125 \mathrm{mM}$ $\mathrm{NaCl}$, the growth increased $30 \%$, with culture optical density $1.1 \pm 0.1$ and $1.3 \pm 0.1$, respectively, compared to untreated stressed cultures $(0.8 \pm 0.1)$, after $48 \mathrm{~h}$ (Fig. 1B). Since the alleviation of the negative impact of salinity was comparable between $50 \mu \mathrm{M}$ and $500 \mu \mathrm{M}$ ABA treatments, we used the lower concentration $(50 \mu \mathrm{M})$ in the next experiments.

For a deeper investigation, it is critical to determine if the salt stress caused cellular death rather than cell inhibition, to understand the mechanisms involved. Using unstressed cultures as a reference, $\sim 60 \%$ of $C$. reinhardtii cells treated with salt survived and formed colonies. In comparison, the percent of cell vitality increased up to $\sim 90 \%$ when ABA was externally added (Fig. 1C). These results were in coherence with the optical density values.

The photosynthetic activities of the cultures were monitored by measuring $\mathrm{O}_{2}$ production at different actinic light intensities in the $\mathrm{P}$ v E curve. C. reinhardtii cells grown under $125 \mathrm{mM} \mathrm{NaCl}$ displayed a lower lightsaturated rate of photosynthesis $\left(\mathrm{P}^{\mathrm{E}}{ }_{\max }\right.$ ) of $4.8 \mu \mathrm{mol} \cdot \mathrm{mmol} \mathrm{Chl}{ }^{-1} \mathrm{~s}^{-1}$ compared to the unstressed control of $9.2 \mu \mathrm{mol} \cdot \mathrm{mmol} \mathrm{Chl}{ }^{-1} \mathrm{~s}^{-1}$ (Fig. 3), indicating that a salinity-induced decline in the rate of photosynthesis is directly responsible for the decrease in cell growth. Surprisingly, when the cultures were incubated with 50 $\mu \mathrm{M}$ ABA the $\mathrm{P}^{\mathrm{E}}{ }_{\text {max }}$ value increased to $20.1 \mu \mathrm{mol} \cdot \mathrm{mmol} \mathrm{Chl}^{-1} \mathrm{~s}^{-1}$ and $12.3 \mu \mathrm{mol} \cdot \mathrm{mmol} \mathrm{Chl}{ }^{-1} \mathrm{~s}^{-1}$, with and without $\mathrm{NaCl}$, respectively, which is $\sim 2-3$ fold higher than the ABA-untreated controls. This result suggests that $\mathrm{ABA}$ does not only protect photosynthesis, but also enhance its rate. 


\section{ABA enhances salinity tolerance in Chlamydomonas by reducing ROS formation in cells}

We used the fluorescent probe $\mathrm{H}_{2}$ DCFDA to estimate the cellular ROS-sensitive fluorescence in Chlamydomonas using confocal microscopy, where the green color indicates the presence of ROS and the red color indicates autofluorescence of chlorophyll (Fig. 4). ROS are natural by-products of cell metabolic processes (Mallick and Mohn, 2000), therefore non-stressed cells were also stained with $\mathrm{H}_{2}$ DCFDA to determine background levels of ROS for quantifying salt-stressed ROS induction compared to the non-stressed control. A very weak ROS green fluorescent signal was observed under control growth conditions. After salt treatment, strong ROS fluorescent signals were detected in the chloroplast and the mock sample, whereas slight ROS signal was observed in the ABA-treated cells (Fig. 4A). These results indicate that ABA decreased the ROS level in cells.

Intracellular ROS accumulation was measured in control and ABA-treated cells following exposure to 125 $\mathrm{mM} \mathrm{NaCl}$ by using flow cytometry. All treatments with $125 \mathrm{mM} \mathrm{NaCl}$ significantly increased intracellular ROS after $3 \mathrm{~h}$ in comparison to controls (Fig. 4B). In ABA-treated cells there was a comparative significant reduction in ROS accumulation. Cells treated with $50 \mu \mathrm{M} \mathrm{ABA}$ induced ROS to $55 \%$ relative to stressed ABA-untreated cells.

\section{ABA treated Chlamydomonas forms less palmelloid cells under $\mathrm{NaCl}$ stress}

The formation of palmelloids in Chlamydomonas was studied using flow cytometry pulse width data as previously described by Chioccioliet al. , 2014, based on cell size. We found that after $12 \mathrm{~h}$ of stress with $125 \mathrm{mM} \mathrm{NaCl}$, palmelloids constituted $30 \%$ of the total cell population which is $\sim 5$-fold of the unstressed control (Fig. 5 \& Supplementary Fig. 5). The remaining was freely motile cells. When assayed for extended time periods $(24 \mathrm{~h})$, the population distribution attained a plateau. However, the formation of palmelloids in ABA-treated cells under $\mathrm{NaCl}$ treatment did not significantly change from the unstressed control, which indicates that $\mathrm{ABA}$ prevents the cells from undergoing changes when exposed to $\mathrm{NaCl}$ stress.

\section{ABA enhances gametogenesis and increases game tolerance to salinity}

Once N depletion was initiated, all cultures continued to grow for 24, After that the growth, based on OD values, of $\mathrm{N}$-depleted control and mock cells slowed till the end of the experiment, suggesting complete cessation of net cell division (Fig. 6). However, the rate of gamete formation in the ABA-treated $C$. reinhardtii cultures increased more than 2 -fold $\left(\mathrm{OD}_{750}=0.86\right)$ of that in the control cultures $\left(\mathrm{OD}_{750}=\right.$ 0.39 ) after $48 \mathrm{~h}$ of induction under normal conditions, before they declined after $72 \mathrm{~h}$.

In comparison, the rate of gamete formation was lower in all cultures under salt stress, with $24 \mathrm{~h}$ extended survival time in ABA-treated cells (Fig. 7).

\section{Discussion}

We examined the physiological phenotyping and chemical responses of $C$. reinhardtii treated with ABA and exposed to salt stresses in order to investigate whether ABA enhances salt tolerance in vegetative cells and gametes of this alga in a similar manner to that in higher plants or not.

The first and immediate indicator for increasing tolerance is the growth rate. Chlamydomonas reinhardtii cells are sensitive to high salt stress and therefore have lower growth rate under such conditions compared to unstressed cells (Hema et al., 2007; Mastrobuoni et al., 2012; Meijer et al., 2017). Yoshida et al. (2003) reported that exogenously added ABA enhances the growth of C. reinhardtii, however it was not clear whether this effect was due to the ABA or the interference of its carrier solvent. In this study, by using ethanol as a mock treatment we confirmed that ABA enhances the growth of microalgae and increases their tolerance to high-salinity stress, where ethanol showed no, or even slightly negative effect on algal growth (Figs. $1 \& 2$ ), unlike in plants where externally added ethanol was proven to increase salt stress tolerance (Nguyen et al., 2017).

It is known that salinity does not exert hostile effects on the stoichiometry and chlorophyll antenna size of the photosynthetic apparatus. However, salinity-stress increases the susceptibility of cells to photoinhibition 
in Chlamydomonas (Neale \& Melis, 1989). When C. reinhardtii was incubated with $125 \mathrm{mM} \mathrm{NaCl}$ for 24 $\mathrm{h}$, as the alga photosynthetic activity recovers up by $\sim 30 \%$ of the original activity after $1 \mathrm{~h}$ of high salt exposure then it remains during the following $24 \mathrm{~h}$ (Vega et al., 2006), a decline in the light-saturated rate of photosynthesis $\left(\mathrm{P}^{\mathrm{E}}{ }_{\text {max }}\right.$ ) was observed (Fig. 3), indicating for PSII photoinhibition. However, ABA-treated cells showed up to $\sim 2$ to 3 -fold increase in the photosynthetic activity under salt stress compared to nontreated cells. These results suggest that ABA can participate in protecting PSII against photoinhibition in C. reinhardtii under high salinity, likely through protecting the cells from $\mathrm{Na}+$ toxicity or less $\mathrm{Na}+$ uptake (Gurmani et al. , 2007), as it has been evidenced that $\mathrm{Na}+$ can irreversibly inactivate photosynthesis systems indirectly by promoting a secondary oxidative disruption, or directly by damaging the photosynthetic $32 / 34$ kDa (D1/D2) proteins as in higher plants (Murata et al., 2007; Yang et al., 2014).

As almost all environmental stresses lead an increase in the production of ROS and thereby to oxidative stress in photosynthetic organisms (Mittler, 2002), the imposition of freshwater algae to salinity stress quickly leads to a rise in ROS in their cells (Mallick \& Mohn, 2000). Indeed, based on ROS-sensitive fluorescence, ROS appeared to accumulate in the stressed ABA-untreated cells and in the stressed mock treatment, and ROS-sensitive fluorescence was especially prominent in the chloroplast (Figure 4A), where the chloroplasts look degraded. In contrast, ABA-treated cells showed weak ROS-sensitive fluorescence with no sign of chloroplasts degradation. The histograms in Fig. 4B clearly supports the microscope images that salinity stress significantly enhanced the intracellular ROS generation in the untreated cells. However, in ABAtreated cells ROS generation was significantly suppressed. These results suggest that ABA induces the elimination of high salinity ROS-reactions in Chlamydomonas cells.

Under different stress conditions such as phosphate limitation (Olsen et al., 1983), acidic environment (Visviki et al., 2000), the herbicide paraquat (Jamers et al., 2010) and high salinity (Khona et al. , 2016) Chlamydomonas cells have alternative ways to avoid chronic stress by forming stress-resistant life cycle stages undergo abnormal cell division with reduced individual cell size forming "palmelloids". In the current study, $\mathrm{NaCl}$ induced the formation of palmelloids in the stressed untreated-cells unlike in ABA-treated cells where the number of palmelloids was significantly reduced (Fig. 5). These results are evidence that ABA playing a crucial role in protecting Chlamydomonas cells from high salinity stress.

In this study, ABA supported the growth of gamete population, as it enhanced their tolerance to high salinity (Figs. 6 \& 7). InChlamydomonas, gametogenesis is triggered by $\mathrm{N}$ limitation. When $\mathrm{N}$ is depleted in the growth medium, the vegetative cells have programs (Beck \& Haring, 1996; Goodenough, 1991). The first program is that the cells acclimate to $\mathrm{N}$ deprivation through metabolic changes, including synthesis of N-scavenging enzymes (Quesada \& Fernández, 1994) and the renewal of ribosomes (Martin et al., 1976). The second program is that the vegetative cells underdo gametogenesis to produce Mt+ and Mt- cells for mating. While N starvation has been extensively studied in Chlamydomonas for producing alternative sources of energy by accumulation more TAG in the cells under N starvation (Montantes et al., 2018; Salas- Siaut et al., 2011; Yang et al., 2020), or as a new tool to create offspring with new traits (Kramer and Lucker, 2020), however, N-starved Chlamydomonas cells can also exhibit various biological pathways for managing photosynthesis to efficiently utilize the absorbed light energy (Saroussi et al., 2017). While underlying these pathways is still in its early stage, it could provide an important direction for developing a more comprehensive understanding of photosynthetic energetics and its control.

\section{Acknowledgments}

We thank Dr. Iftach Yacoby from Tel Aviv University for providing us with the C. reinhardtii culture, and Prof. Assaf Vardi from Weizmann Institute of Science for the scientific discussion. This work was financially supported by Israel Science Foundation (ISF) \# 1681/19. The Author Said Abu-Ghosh dedicates this work to his parents.

\section{References}

Adler, N. E., Schmitt-Jansen, M., \& Altenburger, R. (2009). Flow cytometry as a tool to 
study phytotoxic modes of action. Environmental Toxicology and Chemistry, 26, 297-306.

Asada, K. (1999). The water-water cycle in chloroplasts: Scavenging of active oxygens

and dissipation of excess photons. Annual Review of Plant Physiology and Plant Molecular Biology, 50, 601-639.

Beck, C. F., \& Haring, M. A. (1996). Gametic differentiation of Chlamydomonas .

International Review of Cytology, $168,259-302$.

Bell, G. (2005). Experimental sexual selection inChlamydomonas . Journal of

Evolutionary Biology, 18 , 722-734.

Bruce, V. G., \& Bruce, N. C. (1981). Circadian clock-controlled growth cycle in

Chlamydomonas reinhardtii. In International Cell Biology. H. G. Schweiger, editor. Springer-Verlag, New York. 823-830.

Chen, X., Tian, D., Kong, X. et al. (2016). The role of nitric oxide signalling in response

to salt stress in Chlamydomonas reinhardtii . Planta, 244, 651-669.

Chioccioli, M., Hankamer, B., \& Ross, I. L. (2014). Flow Cytometry Pulse Width Data

Enables Rapid and Sensitive Estimation of Biomass Dry Weight in the Microalgae Chlamydomonas reinhardtii and Chlorella vulgaris. PLoS ONE, 9(5): e97269. doi:10.1371/journal.pone.0097269.

Chokshi, K., Pancha, I., Ghosh, A., \& Mishra, S. (2017). Salinity induced oxidative stress

alters the physiological responses and improves the biofuel potential of green microalgae Acutodesmus dimorphus. Bioresource Technology 244, 1376-1383.

Colle'n, J., Davison, T. R. (1997). In vivo measurement of active oxygen production in

the brown alga Fucus evanescens using 20,70-dichlorohydrofluorescein diacetate. Journal of Phycology, 33, 643-648.

Couso, I., Pérez-Pérez, M. E., Martínez-Force, E., Kim, H. S., He, Y., Umen, J. G.,

Crespo, J. L. (2018). Autophagic flux is required for the synthesis of triacylglycerols and ribosomal protein turnover in Chlamydomonas. Journal of Experimental Botany, 69(6), 1355-1367.

Delaux, P. M., Radhakrishnan, G. V., Jayaraman, D., Cheema, J., Malbreil, M.,

Volkening, J. D., Sekimoto, H., Nishiyama, T., Melkonian, M., Pokorny, L., et al. (2015). Algal ancestor of land plants was preadapted for symbiosis. Proceedings of the National Academy of Sciences of the United States of America, 112, 13390-13395.

Findinier, J., Tunçay, H., Schulz-Raffelt, M., Deschamps, P., Spriet, C., Lacroix, J. M,

Duchêne, T., Szydlowski, N., Li-Beisson, Y., Peltier, G. et al.(2017). The Chlamydomonas mex1 mutant shows impaired starch mobilization without maltose accumulation. Journal of Experimental Botany, 68, $5177-5189$.

Girolomoni, L., Cazzaniga, S., Pinnola, A., Perozeni, F., Ballottari, M., Bassi, R. (2019).

LHCSR3 is a nonphotochemical quencher of both photosystems inChlamydomonas reinhardtii.Proceedings of the National Academy of Sciences of the United States of America, 116(10), 4212- 4217.

Goodenough, U. W. (1991). Chlamydomonas mating interactions. In: Dworkin M (ed)

Microbial cell-cell interactions. American Society for Microbiology, Washington, D.C., pp 71-112. 
Gurmani, A. R., Bano, A., Salim, M. (2007). Effect of abscisic acid and benzyladenine on growth and ion accumulation of wheat under salinity stress. Journal of Botany, 39, 141-149.

Han, X., Zeng, H., Bartocci, P., Fantozzi, F., Yan, Y. (2018). Phytohormones and Effects on Growth and Metabolites of Microalgae: A Review. Fermentation, 4, 25.

Harris, E. H. (1989). The Chlamydomona s source book: a comprehensive guide to biology and laboratory use. Academic Press, San Diego.

Hema, R., Kumar, M. S., Shivakumar, S., Reddy, P. C., Udayakumar, M. (2007).

Chlamydomonas reinhardtii, a model system for functional validation of abiotic

stress responsive genes. Planta, 226 , 655-670.

Jamers, A., De Coen, W. (2010). Effect assessment of the herbicide paraquat on a green

alga using differential gene expression and biochemical biomarkers. Environmental Toxicology and Chemistry, 29, 893-901.

Jokel, M., Johnson, X., Peltier, G., Aro, E. M., Allahverdiyeva, Y. (2018). Hunting the

main player enabling Chlamydomonas reinhardtii growth under fluctuating light. Plant Journal: For Cell and Molecular Biology,94, 822- 835.

Juvale, P. S., Wagner, R. L., Spalding, M. H. (2016). Opportunistic proteolytic

processing of carbonic anhydrase 1 from Chlamydomonas in Arabidopsis reveals a novel route for protein maturation. Journal of Experimental Botany, 67(8), 2339-2351.

Khona, D. K., Shirolikar, S. M., Gawde, K. K., Hom, E., Deodhar, M. A., D’Souza, J. S.

(2016). Characterization of salt stress-induced palmelloids in the green alga, Chlamydomonas reinhardtii. Algal Research, 16, 434-448.

Kramer, D., Lucker, B. F. (2020). Efficient method for selection of high-performing algae isolates and identification of trait genes. US Patent App. 16/445,781.

Lefebvre, P. A., Fitz-Gibbon, S. T., Grossman, A. R., Jonikas, M., C. (2016). An indexed, mapped mutant library enables reverse genetics studies of biological processes in Chlamydomonas reinhardtii. Plant Cell, 28(2), 367-387.

Li, X., Zhang, R., Patena, W., Gang, S. S., Blum, S. R., Ivanova, N., Yue, R., Robertson

J. M. (2016). An indexed, mapped mutant library enables reverse genetics studies

of biological processes in Chlamydomonas reinhardtii. The Plant Cell, 28, 367-387.

Ligrone, R. (2019). Land Plants. In: Biological Innovations that Built the World.

Springer, Cham.

Mallick, N., Mohn, F. H. (2000). Reactive oxygen species: response of algal cells.

Journal of Plant Physiology, 157 (2) 183-193.

Martin, N. C., Chiang, K. S., Goodenough, U. W. (1976). Turnover of chloroplast and cytoplasmic ribosomes during gametogenesis in Chlamydomonas reinhardti. Developmental Biology, 51, 190201. 
Mastrobuoni, G., Irgang, S., Pietzke, M., Aßmus, H., Wenzel, M., Schulze, W., Kempa,

S. (2012). Proteome dynamics and early salt stress response of the photosynthetic organism Chlamydomonas reinhardtii. BMC Genomics, 13, 215.

Meijer, H. J. G., van Himbergen, J. A. J., Musgrave, A., Munnik, T. (2017). Acclimation

to salt modifies the activation of several osmotic stress-activated lipid signalling

pathways in Chlamydomonas . Phytochemistry, 135, 64-72.

Merchant, S. S., Prochnik, S. E., Vallon, O., Harris, E. H., Karpowicz, S. J., Witman, G.

B, Terry, A., et al. (2007). The Chlamydomonas genome reveals the evolution of key animal and plant functions. Science, 318, 245-250.

Miller, G. A. D., Suzuki, N., Ciftci-Yilmaz, S., Mittler, R. (2010). Reactive oxygen

species homeostasis and signalling during drought and salinity stresses.Plant, cell E\& environment, 33(4), $453-467$.

Mittler, R. (2002). Oxidative stress, antioxidants and stress tolerance.

Trends in Plant

Science, 7 , 405-410.

Mittler, R., Blumwald, E. (2015). The roles of ROS and ABA in systemic acquired

acclimation. Plant Cell, 27 (1), 64-70.

Munns, R., Gilliham, M. (2015). Salinity tolerance of crops-What is the cost? New

Phytologist, 208 , 668-673.

Murata, N., Takahashi, S., Nishiyama, Y., Allakhverdiev, S. I. (2007). Photoinhibition of

photosystem II under environmental stress. Biochimica et Biophysica Acta, 1767, 414-421.

Nguyen, H. M., Sako, K., Matsui, A., Suzuki, Y., Mostofa, M. G., Ha, C. V., Tanaka, M.,

Tran, L. S. P., Habu, Y., Seki, M. (2017). Ethanol enhances high-salinity stress tolerance by detoxifying reactive oxygen species in Arabidopsis thaliana and rice. Frontiers in Plant Science, 8, 1-10.

Olsen, Y., Knutsen, G., Lien, T. (1983). Characteristics of phosphorus limitation in

Chlamydomonas reinhardtii (chlorophyceae) and its palmelloids.Journal of Phycology, 19, 313-319.

Quesada, A., Fernandez, E. (1994). Expression of nitrate assimilation related genes

in Chlamydomonas reinhardtii . Plant Molecular Biology, 24 , 185-194.

Rizhsky, L., Liang, H., Mittler, R. (2003). The water-water cycle is essential for chloroplast protection in the absence of stress. Journal of Biological Chemistry, 278, 38921-38925.

Salas-Montantes, C. J., Gonzalez-Ortega, O., Ochoa-Alfaro, A. E., Camarena-Rangel, R.,

Paz-Maldonado, L. M. T., Rosales-Mendoza, S., Rocha-Uribe, A., Soria-Guerra, R. E. (2018). Lipid accumulation during nitrogen and sulfur starvation in Chlamydomonas reinhardtii overexpressing a transcription factor. Journal of Applied Phycology, 30, 1721-1733

Santner, A., Calderon-Villalobos, L. I. A., Estelle, M. (2009). Plant hormones are

versatile chemical regulators of plant growth. Nature Chemical Biology, 5, 301-307.

Saroussi, S., Sanz-Luque, E., Kim, R. G., Grossman, A. R. (2017). Nutrient scavenging 
and energy management: acclimation responses in nitrogen and sulfur deprived Chlamydomonas. Current Opinion in Plant Biology, 39, 114-122.

Scranton, M. A, Ostrand, J. T., Fields, F. J., Mayfield, S. P. (2015).Chlamydomonas as a model for biofuels and bio-products production. Plant Journal, 82 (3), 523-531.

Sharpless, T. K., Melamed, M. R. (1976). Estimation of cell-size from pulse shape in flow cytofluorometry. Journal of Histochemistry and Cytochemistry, 24, 257-264.

Shull, G. H. (1948). What Is "Heterosis"? Genetics, 33 , 439-446.

Siaut, M. S., Cuine, C., Cagnon, B., Fessler, M., Nguyen, P., Carrier, A., Beisson, B. F.,

Triantaphylides, C., Li-Beisson, Y., Peltier, G. (2011). Oil accumulation in the model green alga Chlamydomonas reinhardtii: characterization, variability between common laboratory strains and relationship with starch reserves. BMC, Biotechnology 11, 7-21.

Suzuki, N., Koussevitzky, S., Mittler, R., Miller, G. (2012). ROS and redox signalling in the response of plants to abiotic stress. Plant, Cell \& Environment, 35(2), 259-270.

Takahashi, S., Murata, N. (2008). How do environmental stresses accelerate

photoinhibition? Trends in Plant Science, 13 , 178-182.

Vega, J. M., Garbayo, I., Dominguez, M. J., Vigara, J. 2006. Effects of abiotic stress on photosynthesis and respiration in Chlamydomonas reinhardtii: induction of oxidative stress. Enzyme and Microbial Technology, 40, 163-167.

Vishwakarma, K., Upadhyay, N., Kumar, N., Yadav, G., Singh, J., Mishra, R. K., Kumar.

V., Verma, R., Upadhyay, R. G., Pandey, M., Sharma, S. (2017). Abscisic acid signaling and abiotic stress tolerance in plants: A review on current knowledge and future prospects. Frontiers in Plant Science, 8, 161.

Visviki, I., Santikul, D. (2000). The pH tolerance of

\section{Chlamydomonas applanata}

(Volvocales, Chlorophyta). Archives of Environmental Contamination and Toxicology, 38, 147-151.

Yang, C., Zhang, Z. S., Gao, H. Y., Fan, X. L., Liu, M. J., Li, X. D. (2014). The

mechanism by which $\mathrm{NaCl}$ treatment alleviates PSI photoinhibition under chilling-light treatment. Journal of Photochemistry and Photobiology B: Biology, 140, 286-291.

Yang, M., Kong, F., Xie, X., Wu, P., Chu, Y., Cao, X., Xue, S. (2020). Galactolipid

DGDG and betaine lipid DGTS direct de novo synthesized linolenate into triacylglycerol in a stress-induced starchless mutant of Chlamydomonas reinhardtii. Plant and Cell Physiology, 61(4):851-862.

Yoshida, K., Igarashi, E., Mukai, M., Hirata, K., Miyamoto, K. (2003). Induction of

tolerance to oxidative stress in the green alga Chlamydomonas reinhardtii by abscisic acid. Plant, Cell $\mathcal{E}$ Environment, 26, 451-457.

Yoshida, K., Igaashi, E., Waatsuki, E., Miyamoto, K., Hirata, K. (2004). Mitigation of osmotic and salt stresses by abscisic acid through reduction of stress-derived oxidative damage in Chlamydomonas reinhardtii.Plant Science, 167, 1335-1341.

Figure legends 
Figure 1. The effects of $\mathrm{ABA}$ on growth of vegetative C. reinhardtii cultures under different salinity conditions. A). Time-course kinetics of optical density of cells grown under optimal conditions, and B). under salt stress of $125 \mathrm{mM} \mathrm{NaCl}$ for $48 \mathrm{~h}$. C). Percent of colony forming units (CFU) of cultures grown under salt-stress conditions with and without $50 \mu \mathrm{M}$ ABA and then inoculated on complete TAP agar plates for a 6 -day recovery period. $\%$ is related to unstress conditions. Values are the mean of 6 biological replicates \pm standard errors. Asterisks indicate significant difference compared to ABA-untreated cells and mock cells $\left({ }^{*} P<0.05,{ }^{* *} P<0.01\right)$.

Figure 2. Changes in the light-saturated rate of photosynthesis $\left(\mathrm{P}^{\mathrm{E}}{ }_{\max }\right)$ of C. reinhardtiisubjected to stressing $\mathrm{NaCl}$ concentrations for $24 \mathrm{~h}$ in the presence and absence of ABA. Means of 2 replicates \pm standard errors $(* * * P<0.001)$.

Figure 3. The effect of $\mathrm{ABA}$ on $\mathrm{ROS}$ generation in C. reinhardtii during incubation in the light for $3 \mathrm{~h}$ under $\mathrm{NaCl}$ stress conditions, then adding H2DCFDA stain as a fluorescent probe for ROS. A). Microscope images, green color indicates the presence of ROS; red color indicates autofluorescence of chlorophyll. Size bars $10 \mu \mathrm{m}$. B). Intracellular ROS level was determined by a flow cytometric analysis. Histograms show distribution of the fluorescent intensity of DCF among cell population of $1 \times 10^{3}$ cells $^{*} \mathrm{~mL}^{-1}$. Values are the mean of 6 biological replicates \pm standard errors. Asterisks indicate significant difference compared to ABA-untreated cells and mock cells by paired-sample Student's t test $\left({ }^{* * *} P<0.001\right)$.

Figure 4. Palmella formation indicated by cell diameter per population. Fluorescence activated cell sorting (FACS) of C. reinhardtii cells was used to sort a mixture of cells and beads, according to SSC-W range. Cells and marker beads were photographed after sorting in the range SSC-W $=1 \times 10^{6}$ cells $^{*} \mathrm{~mL}^{-1}$ (cells grown in TAP).

Figure 5. The effects of ABA on kinetics of gamete formation and survival. A). Time-course kinetics of optical density of cells grown under optimal conditions, and B). under salt stress of $125 \mathrm{mM} \mathrm{NaCl}$ for $72 \mathrm{~h}$ $\left({ }^{*} P<0.05,{ }^{* * *} P<0.001\right)$.

Figure 6. Growth and survival of Chlamydomonas gametes after being subjected to salt stress conditions. Cells were serially diluted in water, and $50 \mu \mathrm{l}$-aliquots spotted on TAP-agar plates and incubated for 3 to 5 days, as indicated in A) and B), respectively, under continuous illumination.
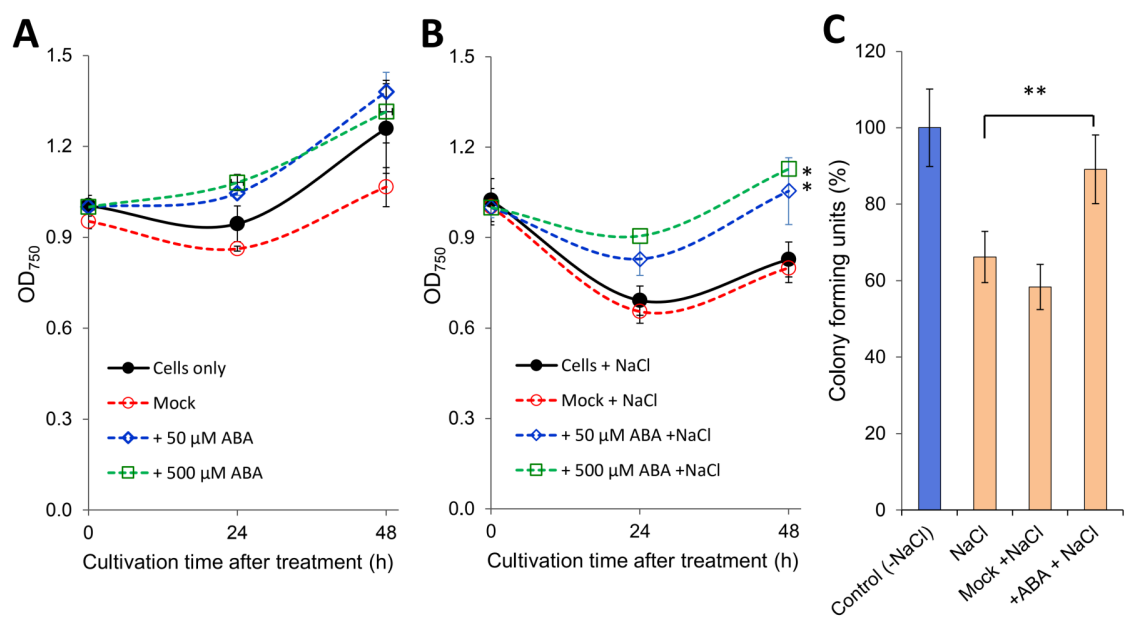


\section{Hosted file}

Abscisic acid to enhance salt tolerance in Chlamy Summary- SA(2).pdf available at https: //authorea.com/users/333975/articles/460086-abscisic-acid-confers-salinity-tolerance-inchlamydomonas-reinhardtii-at-different-stages-of-its-life-cycle 